\title{
20-Year History of Korean Society of Interventional Neuroradiology (KSIN)
}

\author{
Yoo Dong Won, MD', Nam Joon Lee, MD²
}

\section{The birth of the KSIN}

In 1994, at 19:00 on August 30th, eight radiologists pursuing the area of interventional neuroradiology individually returned from overseas conference and gathered at the Sujeong Palace in Dongsung-dong, Seoul for the first time. They were Dr. Dong Ik Kim, Dr. Sun Yong Kim, Dr. Hong Sik Byun, Dr. Dae Chul Suh, Dr. Hae Young Seol, Dr. Gil Woo Lee, Dr. Nam Joon Lee, and Dr. Moon Hee Han whose common interest in interventional neuroradiology research created the Korean Society of Interventional Neuroradiology (KSIN). At the gathering, a number of mandates were initiated: 1) the name of the society would be called 'A Society of Interventional Neuroradiologic Research', 2) a monthly meeting would be held on 2nd Mondays of each month at 18:30 in the conference room of Samsung Medical Center, 3) Dr. Hong Sik Byun of Samsung Medical Center would be responsible (not as president yet) for contacting other members for the monthly meeting, 4) a monthly

\footnotetext{
'Department of Radiology, Uijeongbu St. Mary's Hospital, College of Medicine, The Catholic University of Korea, Seoul, Korea

2Department of Radiology, Korea University College of Medicine, Seoul, Korea

Received January 27, 2015;

accepted after revision February 3, 2015.

Correspondence to: Nam Joon Lee, MD, Department of Radiology, Korea University College of Medicine, 73 Inchon-ro, Seongbuk-gu, Seoul 136-705, Korea.

Tel. 82.2.920.5694 E-mail: njlee@kumc.or.kr

This is an Open Access article distributed under the terms of the Creative Commons Attribution Non-Commercial License (http://creativecommons.org/licenses/by-nc/3.0) which permits unrestricted non-commercial use, distribution, and reproduction in any medium, provided the original work is properly cited.
}

membership fee would be 50,000 Korean Won (KRW), 5 ) initial monthly meetings would be mainly based on case discussions, and 6) the monthly meeting would be open to any radiologist interested in interventional neuroradiology. In the early days, the members faced a number of difficulties; individual purchases of expensive up-to-date medical equipment and products needed for interventional procedures from overseas were common as most equipment and products available at the time were insufficient and imported goods were limited. To make things worse, the national health insurance did not provide coverage for most of the new procedures in the field of interventional neuroradiology and it was up to the interventional radiologists to overcome such difficulties and make progress.

The first monthly meeting was held on Monday of September 12th, 1994 in the conference room at Samsung Medical Center. A total of four meetings were held during that year, ending with a well-deserved end of year celebration in December 1994. The KSIN's first international involvement was at the 1st conference of the Asian Australian Federation of Interventional and Therapeutic Neuroradiology (AAFITN) held during October 2nd-6th, 1994 in Beijing, China where Dr. Dong Ik Kim, one of the co-founders of KSIN, had participated. More international participations of KSIN followed. Dr. Dong Ik Kim was the congress administrator of the 3rd World Federation of Interventional and Therapeutic Neuroradiology (WFITN) held in Kyoto, Japan on November 19th-22nd, 1995. Dr. Sun Yong Kim and Dr. Moon Hee Han gave oral presentation and displayed poster exhibition respectively, for which Dr. Han received the award for best poster presentation.

In September 1996, Dr. Hae Young Seol of Guro 
Korea University Hospital was elected as the first president of KSIN and Dr. Hong Sik Byun of Samsung Medical Center held the secretary position of KSIN. The society's mandates and member lists were officially written and membership fee was fixed as 100,000 KRW for full-membership and 50,000 KRW for members in fellowship. Also, the date of monthly meeting was changed to 1 st Tuesday of each month to draw more participants. More KSIN members had opportunities to participate in the 4th and 5th WFITN held in New York City (September 13th-16th, 1997) and in Portugal (June 4th-8th, 1999) respectively. Furthermore, Dr. Byung Hee Lee and Dr. Hae Woong Jeong made significant contribution to the growing influence of KSIN at international level by participating in the 3rd AAFITN held in Sendai, Japan in November 2000 with poster exhibitions.

On July 3rd, 1999, the monthly meeting was first held outside Seoul under the name of 'Regular Research Conference'; four KSIN members gave presentations on the topic of 'Interventional treatment of dural arteriovenous fistula' at Chonnam National University Hospital in Gwangju (Fig. 1). The KSIN saw its 2nd president, Dr. Dong Ik Kim of Yonsei University Severance Hospital with Dr. Byung Hee Lee of Bundang Cha Hospital as new secretary in September 1999. From this point on, the monthly meeting had started to take place in different locations. On November 13th, 1999, a first joint conference of neuroradiologists and neurosurgeons (Neurovascular Surgery Society; currently SKEN) was held at Gangnam St. Mary's Hospital. The conference had the opportunity to have Dr. In Sup Choi from USA and Dr.
Pierre Lasjaunias from France who delivered wonderful lectures on topics such as 'Percuetaneous Vertebroplasty', and '3D Angiography and Cerebral Aneurysm'. In the meantime, a manual of 'Procedural Materials in Interventional Neuroradiology' was published in November 1999. Dr. Moon Hee Han of Seoul National University was the editor-in-chief of the manual that contained detailed information and figures on procedural materials. A symposium first led by the KSIN in Korean Society of Radiology's annual spring conference was held on April 22nd, 2000 in Gyeongju where Dr. Dong Ik Kim, Dr. Hong Sik Byun, Dr. Moon Hee Han and Dr. Sun Yong Kim participated as lecturers. Soon after, the KSIN's spring symposium was first held at Pusan Baik University Hospital on May 13th, 2000. A total of 27 members participated, four of whom were lecturers. This spring symposium continued in different cities annually in April from 2003. The spring symposiums in 2003 and 2004 were special in that they were hosted by KSIN together with the Korean Society of Neuroradiology. From this point on, the spring symposiums intended to promote membership intimacy while the autumn conferences focused more on academic lectures and exchange of experience and knowledge.

\section{The Growth of the KSIN}

At the general meeting of KSIN on April 11th, 2000, a new set of mandates was first implemented and new select committees were elected. The select committees were made up of 7 members including president, vicepresident, inspector, secretary, and 3 managers in

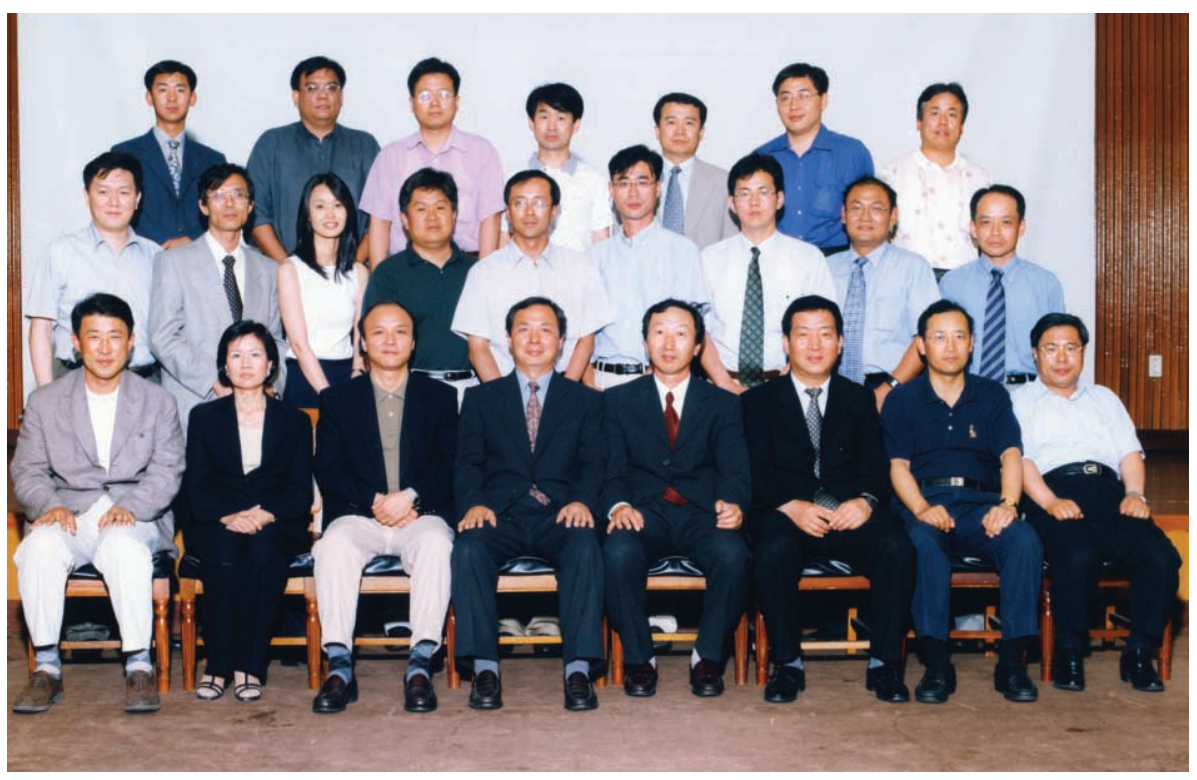

Fig. 1. KSIN Symposium, Gwangju, 1999. 
finance, academics, and special occasions on a 2-year term. The general meeting of KSIN would be held once a year and the mandates consisted of 6 categories in membership, executives, business, finance, regulations, general rules and meetings. In addition, the English name of the society was first decided as 'Korean Society of Interventional Neuroradiology'. In particular, in accordance with KSIN's 4th article of the 2nd chapter, which states "A member shall adhere to the founding purpose of KSIN and promise to follow its regulations in that he or she must be a specialist of related medical fields in order to promote maturity of KSIN", the society opened its door to medical professionals in other fields of specialty. At the time, there were 44 specialists with full-membership. Dr. Moon Hee Han of Seoul National University published the KSIN's official seal and logo in March and September of 2001.

The 6th WFITN and 4th AAFITN were hosted at Seoul Hilton Hotel on September 23rd-26th, 2001 (Fig.

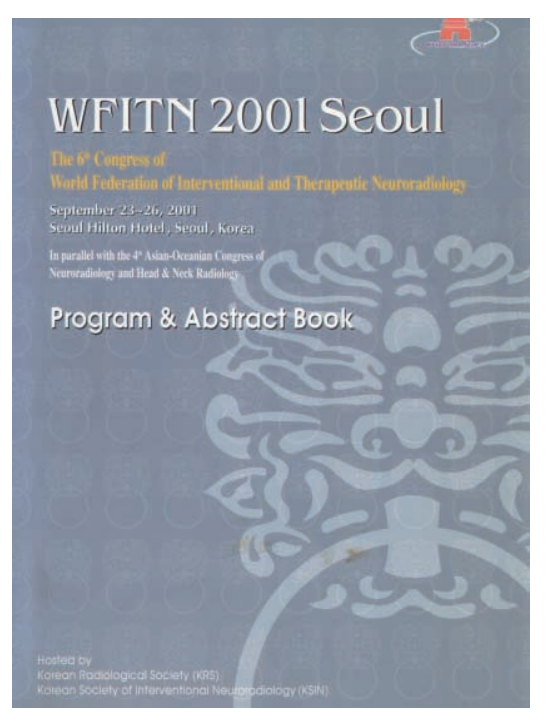

Fig. 2. 6th WFITN, Seoul, Korea, 2001.
$2)$. Even though this was a turbulent period immediately after the 9.11 terror attacks in the U.S., 697 participants from 31 countries had visited the congress which marked the beginning of Korea's growing role in interventional neuroradiology on a global scale. Dr. In Sup Choi (president of WFITN congress), Dr. Dong Ik Kim (organizing committee chairman), and Dr. Moon Hee Han (congress secretary) spearheaded the congress successfully. During the congress, 119 lectures and 137 poster exhibitions were presented of which 10 oral presentations, 19 posters, and 1 lecture were presented by Korean participants.

Dr. Nam Joon Lee (Korea University) was elected as 3rd president of KSIN and a neurosurgeon, Dr. Yong Sam Shin (Ajou Univeristy) as secretary in November 2001. The KSIN was listed as subsidiary society of the Korean Society of Radiology (KSR) in March 2003 and was officially approved and registered in June of the same year. In 2004, the KSIN strengthened its academic involvement by publishing 3 categorical courses, 12 oral presentations, and 7 poster exhibitions at the Korean Congress of Radiology, an official autumn congress hosted by KSR. The first summer symposium of KSIN was held at the Jeju Sunshine Hotel on August 22nd-23rd, 2003 (Fig. 3). This symposium was distinct from other ones in its discussion on introduction of procedural instruments, intensive lectures on treatment of a variety of diseases and procedural complications. With invitation of members' families, over 100 participants made the first summer symposium successful.

At the spring conference in 2004, Dr. Moon Hee Han (Seoul National University) was elected as 4th president of KSIN and Dr. Ha Hun Song (Uijeongbu St. Mary's Hospital) as secretary, who, however, on personal reasons, was succeeded by Dr. Pyoung Ho Yoon (Ilsan Hospital of National Health Insurance Corporation) in September. From 1999 to 2003, the

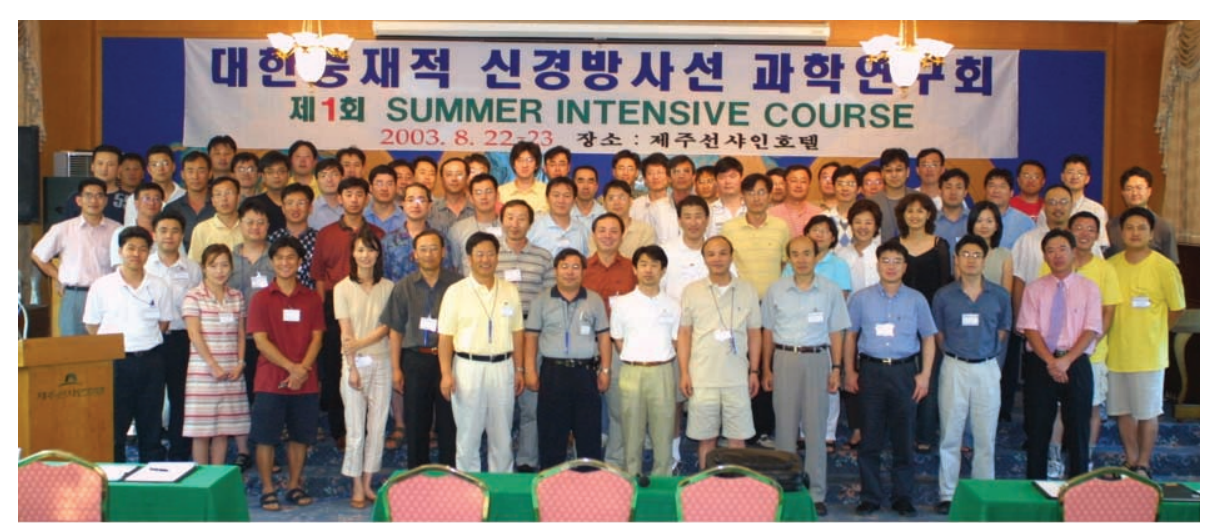

Fig. 3. The first Summer Intensive Course, Jeju, 2003. 


\section{Yoo Dong Won, et al.}

KSIN hosted four consecutive joint autumn congresses with 'Society of Korean Endovascular Neurosurgeons' until November 6th, 2004 when KSIN hosted the congress on its own. The congratulatory speech for the 10 th anniversary of 'Society of Interventional Neuroradiology' was given by the president of KSIN, Dr. Moon Hee Han, during which there were 82 full members and 22 business associate members. Dr. Randall T. Higashida from UCSF was a notable participant at the time. At the general meeting held in April, 2005 , the society's official name as KSIN was suggested and finalized in May.

On Wednesday of December 21st, 2005, a first imaging conference for in-training radiologist residents was held at Samsung Medical Center. This conference had continued annually on 3rd week of Wednesday in December. On July 14th, 2007, the KSIN-led training sessions for radiologist residents had first started. These sessions were mostly lectures on basics of interventional neuroradiology designed at the level of residents. A total of four training sessions were held from 2009 to 2012 .

Dr. Hong Sik Byun of Samsung Medical Center (Sungkyunkwan University) became the 5th president of KSIN and Dr. Pyoung Jeon as secretary on April 7th, 2006. On October 26th, 2006, the first China Korea Scientific Exchange on Interventional Neuroradiology (CKSE) was held. This congress was designed to promote exchange of knowledge in interventional neuroradiology between the two countries and consisted of 9 lectures by each country. Invited lecturers were Dr. In Sup Choi and Dr. Lasjaunias. Until 2009, this congress was held four times in both countries and became the preliminary model for the East Asia Conference of Neurointervention (EACoN) which had started from 2010 until today.

\section{The Maturation of the KSIN}

Dr. Dae Chul Suh of Asan Medical Center (Ulsan University) was elected as 6th president of KSIN and Dr. Eui Jong Kim of Kyung Hee University as secretary on April 12th, 2008. At the autumn congress held on November 8th, 2008, a new training session called 'Updated Neurointervention Refresh Course' was first introduced and six scholars from radiology, neurosurgery, neurology, cardiology, and radiologic science research center delivered most up-to-date lectures. On 2010, Dr. Yong Sun Kim of Kyungpook University became the 7th and first president of KSIN outside Seoul. Dr. Bum Soo Kim of Seoul St. Mary's Hospital was elected as secretary. The KSIN played an active role in the Asia Pacific Congress of Cardiovascular and Interventional Radiology (APCCVIR) hosted in Seoul on June 1st, 2010 by giving 8 oral presentations and 1 poster exhibition. On June 13th, 2010, the first EACoN hosted by Korea, China, and Japan took place in Kobe, Japan. 23 members of KSIN participated in this congress and gave 13 oral presentations. On December 10th, 2011, the annual autumn congress of KSIN changed its opening month from November to December and combined the end of year celebration-which was normally held after the resident imaging conference in December-in order to attract more participation of members.

On April 14th, 2012, Dr. Pyoung Jeon of Samsung Medical Center (Sungkyunkwan University) became the 8th president of KSIN and the secretary position was held by Dr. Byung Moon Kim of Yonsei University Severance Hospital. The 3rd EACoN was hosted in Jeju Ramada Hotel from August 31st to September 1st, 2012 (Fig. 4). After the first congress in Kobe, Japan in 2010 and 2nd in Shanghai, China in 2011, the 3rd EACoN was held for the first time in Korea and the 10th Summer Intensive Course was concurrently held, making the congress more fruitful than ever. On December 8th, 2012, a neurosurgery society called Society of Korean Endovascular Neurosurgeons (SKEN) joined KSIN in hosting a joint academic conference where distinguished Dr. Seon Kyu Lee of University of Chicago delivered a detailed lecture on 'Current Status of Neurointerventional Surgery in the US'. The 12th WFITN was hosted in Buenos Aires, Argentina on November 9th-14th, 2013. A total of 37 Korean members actively participated by giving 5 lectures, 16 oral presentations, and 47 poster exhibitions. In addition, at the 11th AAFITN held in Danang, Vietnam on March 26th-28th, 2014, 45 Korean members showed active enthusiasm in neurointervention by participating as congress administrator, 2 inviting lecturers, 5 lecturers, 27 oral presenters and with 48 poster exhibits. At the 5 th EACoN held in Shanghai on October 30th, 2014, the KSIN participated with 1 lecture, 12 oral presentations and 6 poster exhibitions.

Dr. Bum Soo Kim of Seoul St. Mary's Hospital (The Catholic University of Korea) became the 9th president of KSIN and Dr. Sang Hyun Suh of Gangnam Severance Hospital as secretary on April 12th, 2014. There are 15 members in the current 9 th executive committee of KSIN, which is a double from the initial 7 executive committee members. As of October 2014, 
the KSIN became an independent society outside the KSR. On December 13th, 2014, the KSIN's 20th anniversary academic congress was held at Seoul St. Mary's Hospital. In celebration of this, Dr. Dong Ik Kim's ceremonial speech along with Dr. Yoo Dong Won's 20-year commemoratory speech paved the way for the future visions of KSIN (Fig. 5).

Currently in January of 2015, a total of 281 members (201 full members, 40 semi-members, 40 business associate members) are actively involved in KSIN. Specialists with radiology, neurosurgery and neurology backgrounds comprise the KSIN, each contributing its own field of specialty for the betterment of KSIN.

\section{The Development of the journal "Neurointer- vention"}

At the summer symposium in Muju during August 19th-20th, 2006, the first issue of official journal of our society 'Neurointervention' was released (Fig. 6). Dr. Moon Hee Han, the KSIN president in 2005, had first suggested the idea of publishing an academic journal. The academic manager at the time, Dr. Eui Jong Kim of Kyung Hee University did not hesitate in initiating the process. It was decided that the journal would be published in Korean language bi-annually (Feburary and August) and as Dr. Moon Hee Han's suggestion, 'Neurointervention' became the official title of the journal. Dr. Eui Jong Kim became the first editor-inchief of the journal and there were 12 editor committees. The KSIN president, Dr. Hong Sik Byun wrote congratulatory words in the initial publication and previous presidents, Dr. Hae Young Seol, Dr. Nam Joon Lee, and Dr. Moon Hee Han each wrote words of
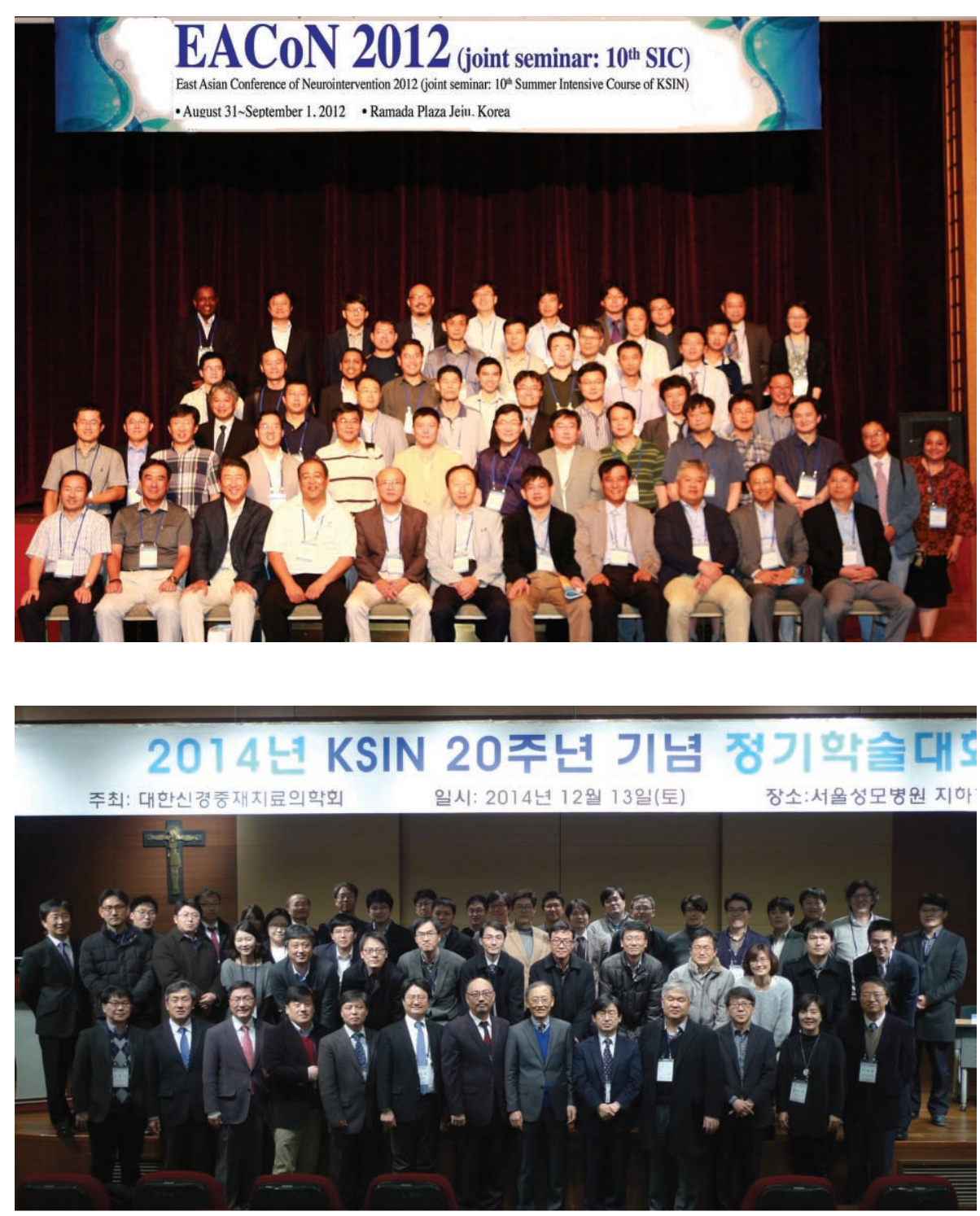

Fig. 4. Third EACoN, Jeju, 2012.

Fig. 5. KSIN's 20th Anniversary Annual Meeting, Seoul, 2014. 


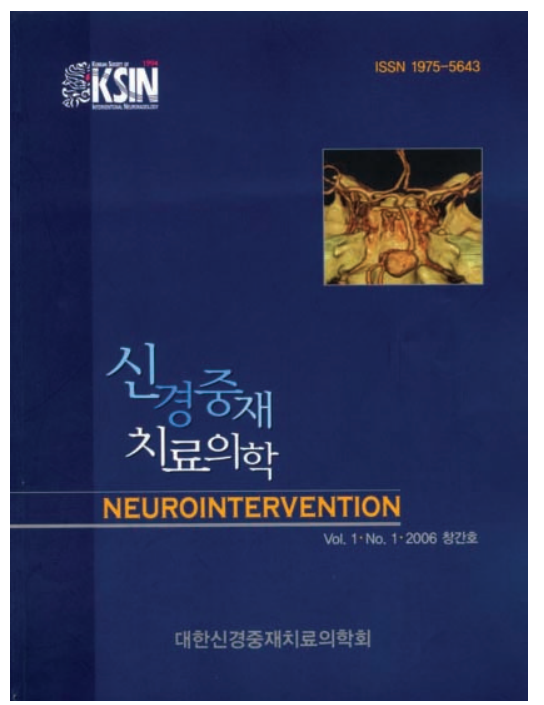

Fig. 6. Cover of the first issue of Neurointervention.

encouragement. Three review articles and 11 case reports were published in the initial issue. In August 2008, the 2nd editor-in-chief was held by Dr. Moon Hee Han, and assistant editor by Dr. Chang Woo Ryu (Kyung Hee University Gangdong East-West Neo Hospital) who after a year became the 3rd editor-inchief. Remarkable growth of the journal soon followed. From January 2011, the journal was listed in Koreamed as member of Korean Association of Medical Journal Editors and its first online website (www.neurointervention.kr) was created. The journal had modified its publishing language from Korean to English. A first modification for introduction to authors was made and the journal further stepped forward by being listed in more widely known PubMed and PubMed Central. In February 2012, the journal published the first article written by international authors. In August 2012, submission website for the journal was opened and in September, eight notable international editors became part of the journal. On September 1st, 2013, one additional international editor joined, making a total of 24 editors. Dr. Woong Yoon of Chonnam National University became the 4th editor-in-chief and currently is struggling for indexing the journal in the $\mathrm{SCI}(\mathrm{E})$.

\section{Meetings in local KSIN branches}

\section{(1) Busan-Ulsan-Kyungnam Branch}

The Busan-Ulsan-Kyungnam(BUK) branch was established after a well-planned preparatory meeting on September 23rd, 2006. A monthly conference of this branch had started from October 11th, 2006 with Dr. Ki Sung Kim as president, Dr. Tae Hong Lee as secretary and Dr. Soon Chan Kwon as academic director. The first opening ceremonial symposium of BUK branch was hosted at Dong-A University on January 19th, 2007 with 9 members. The president Dr. Kim gave the opening speech, and Dr. Hong Sik Byun-the president of KSIN-delivered a speech of encouragement. Dr. Yang Kwon-president of society of Korean Endovascular Neurosurgeons-gave ceremonial words. The symposium ended successfully with informative lectures given by 8 members. Dr. Seung Kug Baik, Dr. Hong Dae Kim, and Dr. Dae Sub Choi were elected as $2 \mathrm{nd}, 3 \mathrm{rd}$, and 4 th president of BUK respectively in 2009, 2011 and 2013. In December 2013, the name of BUK was changed to BUK Neurointervention Society and 10 meetings would be held annually, two of which would be held with the Daegu-Kyungpook Branch. As of December, 2014, there are a total of 36 active members in BUK branch consisting of members in KSIN, SKEN, and vascular neurosurgeons.

At the general meeting, Dr. Yong Woon Cho was elected as the 5th president on a two year term, and Dr. Jin Young Jung (Dong Eui Medical Center) as secretary.

\section{(2) Daegu-Kyungpook Branch}

The first meeting of Daegu-Kyungpook Branch took place in Dr. Yong Sun Kim's office room in November 2005. The monthly meeting would be held on the last week of Friday. The eight initial members were Dr. Yong Sun Kim, Dr. Seung Kug Baik, Dr. Woo Mok Byun, Dr. Chul Hun Jang, Dr. Chang Young Lee, Dr. Chul Ho Sohn, Dr. Ho Kyun Kim, and Dr. Jae Hoon Cho. In December 2007, the branch name was decided to be called 'Neuroclub'. In December 2012, Neuroclub joined the Daegu-Kyungpook(DK) branch of SKEN and their meeting was to be called the DK branch of 'Neuroclub-SKEN'. Five meetings are held annually and two of them are held with BUK Neurointervention Society in May and Novemeber. Since 2014, these meetings are held with other branches in Pohang and Andong and as of December 2014, there are 38 active members. 